Keywords: Mediation; objects; social remembering; agency

The Mediating Role of Objects in Recollections of Adult Women Survivors of Child Sexual Abuse

Paula Reavey \& Steven D. Brown

Dr Paula Reavey

Department of Psychology

London South Bank University

103 Borough Road

London

SE1 OAA

reaveyp@Isbu.ac.uk

Professor Steven D. Brown

School of Management

University of Leicester

Leicester

LE1 7RH

s.d.brown@leicester.ac.uk 


\title{
The Mediating Role of Objects in Recollections of Adult Women Survivors of Child Sexual Abuse
}

\begin{abstract}
Recollection of child sexual abuse involves complex issues of agency - both in the past and in the present. Adult women survivors face the further obstacle of ingrained cultural tendencies to question women's testimony. Ambiguity and ambivalence is found adult women's accounts of their past abuse, but presents particularly dilemmas. Drawing on social remembering approaches developed in 'memory studies', it is argued that recollections have to negotiate issues of incidence and intentionality in the past, as well as the potential contribution made by non-human participants (e.g. objects, spaces, bodies). Using examples from interviews with survivors of child sexual abuse, we illustrate how objects (largely domestic objects and spaces) emerge in the memories as a way of posing and subsequently disposing ambiguity. Objects as well as humans 'modify the state of affairs' (Latour, 2005) and serve as the means to punctualise recollected episodes. An analytic approach sensitive to the role of objects is recollection is offered which is grounded in material-semiotics.
\end{abstract}


Memories lie slumbering within us for months and years, quietly proliferating, until they are woken by some trifle and in some strange way blind us to life. How often this has caused me to feel that my memories, and the labours expended in writing them down are all part of the same humiliating and, at bottom, contemptible business! And yet, what would we be without memory? We would not be capable of ordering even the simplest thoughts, the most sensitive heart would lose the ability to show affection, our existence would be a mere never-ending chain of meaningless moments, and there would not be the faintest trace of a past. How wretched this life of ours its! - so full of false conceits, so futile, that it is little more than shadow of the chimeras loosed by memory. (WG Sebald, 2002: 255)

\section{Introduction: Memory, agency and child sexual abuse}

During one of the many detours into the past that WG Sebald makes in the course of his perambulations detailed in The Rings of Saturn, the musings of the Vicomte de Chateaubriand on the relationship between memory and agency are discussed. Chateaubriand speaks of the fundamental paradox of memory. Without a link to the past we would be unable to lend continuity to existence, to order and experience the unfolding of our lives. But at the same time this link weighs heavily upon us - the regret at things done and things not done, the contrast between what might have come to pass and how things actually are. The past is a lure for our current thoughts - 'so full of conceits, so futile'. There is, for Chateaubriand, something profoundly humiliating in the business of telling one's past, for memory is what simultaneously lends sense to and compromises the present moment.

Sebald's use of Chateaubriand has the further purpose of pointing out a second, more subtle paradox. To regret what has come to pass implies that one had some choice in the past, some ability to decide a course of action, however circumscribed. What though if it there was in fact no moment of discretion, no point where a decision could be made? Furthermore, what if our ability to speak 
of the past from our present position were itself compromised? Chateaubriand has the comparative luxury, however humiliating he finds it, to speak authoritatively of his own life. But when the past that is recalled is painful, traumatic or abusive then the very act of remembering is rendered problematic since a lack of agency in the past has powerful effects on one's present perspective. If a sense of self and current agency are afforded by the link to the past, then what does it mean to recall a past where this freedom and selfdetermination are negated? What if the past itself bordered on the unspeakable?

In this paper we want to examine some of the particular dilemmas and ambiguities experienced by adult women survivors as they discuss recollections of childhood sexual abuse. Such recollections are typically formally understood with reference to juridical concerns over 'true' or 'false' recall (Hacking, 1995; Campbell, 2003). Womens' testimony about their past abuse is thereby considered in terms of its literal accuracy. However, there are widely reported and well known cultural obstacles confronted by adult women who report instances of sexual violence which renders their ability to offer testimony to their own past as being subject to comparatively greater levels of scrutiny (Herman, 1992; Haaken, 1998; Reavey, 2003). This tendency to see women as 'unreliable rememberers' may in part be derived from the history surrounding women's greater suggestibility and removal from ideals of the rational self, relying as it does, on notions of reasoned action and agency (Burman, 1994; Hacking, 1995; Campbell, 2003). The 'subject' of agency is often more readily aligned to the 'masculine', where reason and independence, and thus agency, is more culturally readable, given (perceived and actual, in some cases) biological and cultural constraints on women (Moore, 1994). It is Chateaubriand, with his reasoned and all-knowing reflective recollections on his own past which serves as the model, rather than the conflicted, self-doubting and half-spoken testimony which so often characterises women's memories of child sexual abuse. 
Given this, it may seem entirely counter-productive to raise the question of what ambiguity means in relation to such memories, since it may appear to reinforce the bias against womens' testimony. Adult recollections of child sexual abuse for both men and women - contain clear and explicit references to experiences of powerlessness, violation and lack of agency in the past (Warner, 2000; Baker, 2002). Abusive relationships leave an indelible mark on the person abused, because it represents precisely their inability to be an 'actor' in the relationship which can prevent them from conceiving themselves positively (as an agent) in their relationships with others (Herman, 1992). 'Choice' and 'consent', for example, (the key tenets of agency) are deeply problematic when it comes to addressing women's sexuality, when the numerous obstacles that prevent adult women (as well as other minoritised groups) from accessing agency and action are considered (Holland et al, 1998; Gavey, 2005). Furthermore, women's sexual agency, especially in childhood, is more easily aligned to a victim role, a role that continues into the present. The 'damage' created by abuse is perceived to continue unabated into adulthood, as women are perceived as more likely to 'repeat' the abuse, unless interrupted by therapeutic intervention (O'Dell, 2003). Thus, the chains of meaning, linking past (lack of agency) with present (obstacles to agency) are more easily established for women, as their position as agent in adulthood is already questionable, given the cultural linking of the masculine with agent. This is further confirmed when coming across a growing body of literature on men's early sexual experiences. The label 'child sexual abuse' can more readily be substituted with the term 'age discrepant intergenerational sexualities', wherein discourses of sexual pedagogy and 'positive' expressions of early sexualities, rather than straightforward sexual villainy, is more thoroughly explored (c.f. Weeks, 1985; 2003).

Nevertheless, in previous work we have argued that women's memories contain numerous examples of ambivalence and dilemma, if one examines recollections more closely (Reavey, 2003; Reavey \& Brown, 2006; 2007; Reavey, in press). Through detailed examinations of qualitative data, involving interviews with 
women who have experienced child sexual abuse, we have found that one of the organising features of these memories are not clear cut presentations of the past, where a traditional narrative of the male villain and female victim shape readings of agency, but a tremendous dilemma over how to read self agency and the agency of others (including the abuser in the past and other people in the present). The difficulty here is that child sexual abuse has developed as a master narrative that has shaped interpretations of the present, including present identity and agency (Haaken, 1998; 2003; Reavey, 2003). But the clarity which is provided by this narrative is problematic because it leads us immediately back into the paradox of Chateaubriand's 'wretched life'. To live as a victim is to live with the 'chimeras loosed by memory' rather than as the active agent who can make a reflective turn on their own past in ways that reinforce choice. What we will seek to argue is that acknowledging an element of ambiguity in recollected past episodes is crucial to maintaining a sense of agency in the present. However, as we will hope to demonstrate, ambiguity is mediated by material aspects of the setting in which abuse originally occurred.

\section{Social Remembering}

Our approach to recollections of child sexual abuse is guided by the emerging field of 'memory studies'. This term covers a broad gamut of work ranging across the natural and human sciences and philosophy which emphasises the social dimensions of memory and memorial practices (a very partial list of recent summaries might include see Antze \& Lambek, 1996; Brown, 2008; Campbell, 2003; Daaisma, 2000; Erll \& Nünning, 2008; Haaken, 1998; Haaken \& Reavey, 2009; Lowenthal, 1985; Misztal, 2003; Middleton \& Brown, 2005; Middleton \& Edwards, 1990; Schachter, 1996; Schachter \& Scarry, 2001; Sutton, 1998; Young, 2005; Wertsch, 2002). As these summaries make clear, the variety of work in this area offers up very different conceptualisations of what exactly 'memory' is and what kinds of human activities fall under its overly broad remit (see Brown, 2008). Nevertheless we can safely assert that a common thread which runs through them all is the notion that memory is not a passive faculty of 
recording and storing the past (a 'reproductive' notion of memory) but is rather an active process in which persons engage to make sense of their own personal and collective histories (a 'reconstructive' notion of memory). The person as an actor, rather than mere recipient of social context and structure is a central organising principle here (Chamberlayne et al, 2000). Our own approach has strong sympathies with the latter notion.

From memory studies we draw two major themes which we find useful for approaching recollections of child sexual abuse. First of all, that past abuse is not simply 'given' to memory, but is rather subject to continuous reflection and (re)interpretation by adult survivors (Haaken, 1998; Ronai, 1995). This interpretative process is inflected by the cultural resources which are available to survivors at any given time. One major extant resource in Western Europe and North America is the readily available 'psycho-therapeutic' language that reformulates previous experiences of abuse into fairly set categories (victim/survivor) (Kahn \& Mathie, 2000). Some commentators have pointed to the overly prescriptive role that such a language can serve in the reorganisation of prior experiences of abuse, since it tends to efface the specificities of such memories in favour of a dominant interpretative repertoire (O'Dell, 2003; Reavey, 2003).

The second theme is that memories are never really settled, in the sense of being 'finished off' or 'completed' in some sense. Rather there are elements of ambiguity and indeterminacy which persist throughout all attempts to recollect prior experiences (Middleton \& Brown, 2005). For example, Haaken (1998) points to how some experiences of abuse can be layered with examples of both pleasure (emotional warmth) as well as pain, as well as feelings of love and hate towards an abuser. Ambivalence relating to the intention of the abuser, as well as their own 'participation' in the abuse is present in many memories of child sexual abuse, especially when the child is otherwise attached to the person abusing. In Sylvia Fraser's 'classic' autobiography of incest, she speaks of the enormous 
confusion she felt for a man who inhabited multiple contradictory roles in her imagination, as a loving father and wilful rapist.

If the first theme directs us towards the role of well embedded cultural narratives in making sense of experiences of abuse, then the second turns us back towards the dilemmas and ambiguities in interpretation which the adult survivor faces. There are parallels here with semiotic approach to disclosures of child sexual abuse adopted by Jensen (2005), where abuse becomes a contested 'sign' to be deciphered in the present. As Molina \& del Rio (2007) argue in their perceptive commentary on this work, the dominance of a particular interpretative framework should not blind us to the presence of ambiguity in situated acts of interpretation, nor to the notion that such ambiguity may serve a productive role in that opens the way for further elaboration of meaning.

What is at stake here is grasping how a present sense of agency is formulated and reformulated by adult women survivors when confronted with the interpretative dilemmas of recollected past abuse. To do so we need to understand how individual memories enter into continuous dialogue with culturally available stories which act to anchor recollections of abuse. This is a process Janice Haaken (1998) refers to as 'transformative remembering'. Haaken demonstrates how the meaning of abuse is altered in the course of telling and re-telling. When a memory of abuse is recalled, it has the potential to transform wider cultural issues and more 'banal' female grievances (e.g. neglect or emotional abuse) into a primary narrative of enlightenment ('I've been abused') that can serve to explain and recuperate all of the 'undesirable' feelings that women may have into one overarching narrative of violation (Reavey \& Brown, 2006). In doing so individual experience becomes fused with the social influences that run through the fabric of memory, as well as the cultural constructions of femininity and the emotional power of the immediate context in the telling of that memory (the power of the juridical context, for example). 
Personal memory and autobiography are thus inseparable from the historical, social and cultural conditions of its use (Rasmussen, 2002).

\section{Interdependencies in remembering}

Attending to the ways in which historicity enters into personal and collective memory has been a central concern for socio-cultural studies of 'mind' (Vygotsky, 1978). The interdependency of the collective and individual, the public and private, for example, all work to establish how people position themselves in memory, and what is rendered meaningful and significant, at a personal and public level. What constitutes a 'public' or 'private' issue, and where we posit ourselves in relation to this as moral and 'mindful' agents, is in part defined by the boundaries established by a collective (historical) consciousness (Duncan, 1996). This is particularly important in discussing matters of child sexual abuse, as one of the key ways in which women feel blameworthy or shameful is in the secretive and private manner in which the abusive relationship occurred (Warner, 2000; Baker, 2002). A most important step towards addressing such emotions has thus been to transform 'psychological' issues and 'private' ruminations into matters of public concern and debate in feminist approaches (Brownmiller, 1978; Kelly, 1988; Kitzinger, 1992; Armstrong, 1994).

Participation in a particular community, thus, entails awareness of the history shaping that community and an individual's memory of it (Middleton, 2002; Middleton \& Brown, 2005). As well as the importance of historical consciousness, interactional exchanges, (embedded in both intimate and collective relationships), collective memory and group membership all cede personal interpretations of the link between past and present. If we take seriously social remembering approaches to memory, it is necessary to account for the various interdependencies structuring these social processes (Brockmeier, 2002). By interdependencies, Brockmeier is referring to the impossibility of thinking about 'personal memory' without consideration of the socio-cultural processes and symbolic resources that mould it. 
Two aspects regarding interdependency, in particular, stand out in relation to matters of agency in memory, which we will address in the analysis section in more detail. The first involves how individuals take account of whether their past experiences involve an 'incidence' or an 'intention' in the discursive and rhetorical organisation of text (see Middleton, 2002). An incidence refers to an event that occurs outside of intentional awareness, whereas intention refers to an event that is motivated and agentic. Here we are concerned with how certain memories are considered to be incidental features of action, or intentional, as they serve to orient the individual towards an understanding of themselves (personal), and their standing in relation to others (collective). The person thus exists in parallel with collective concerns regarding moral responsibility and identity. If a past episode is constituted as 'intentional', for example, specific issues relating to moral actions in the future are more likely to be salient. This is precisely the dilemma that many women who have experienced abuse face, as the intentional status of memory can continue to project into past and future questions over responsibility, agency and identity.

Secondly, we ask whether this 'orientation' is conventionalised via discursive social practices only (discourse, conversational exchanges or story-telling practices). That is, whether the agentic aspects of what happened then and what it is to recollect them now are organised exclusively through the various historical grounded narrative and rhetoric devices available to adult women survivors. Is discourse sufficient? If it were this would suggest that ambiguities around recollection could be resolved by drawing on the appropriate discursive resources (e.g. a discourse of early victimhood), or, alternatively that ambiguity is a structural feature of the discourses in which child sexual abuse can be narrated. Neither alternative is in fact the case. We have found that our participants recollections do not straightforwardly fit into a single 'master narrative'. Ambiguities persist around the nature, meaning and present relevance of what was experienced (although it is important to emphasise not around the 
details of what actually happened). Furthermore such ambiguities are troubling and difficult to manage for participants. They are not rhetorical aspects of some discourse but rather refer to precisely those things which are difficult to clearly situate into a clear narrative understanding.

Women seemingly have little to gain by invoking ambiguity and indeterminacy in their recollections of child sexual abuse. It does not apparently assist with creating either personal or collective cohesion in relation to a remembered past (i.e. my own abusive history, my place in women's historical role as victims). Our argument is that it is precisely by disrupting such interdependencies, by keeping open questions of individual and collective identity, that women are able to demonstrate agency in the present. This is done by raising questions of their own and others agency and participation in the past with respect to the abuse (see Reavey \& Brown, 2006; 2007). Clearly to even begin to articulate such ambivalence is profoundly threatening, since it carries the risk of being treated as an unreliable rememberer or of been seen to be identifying with the abuse or abuser(s). Ambiguity must then itself be managed. If it is not resolved through narrative means then how is this done?

\section{Mediation and memory: human and non-human participation}

Edward Casey (1987), in a phenomenological study of autobiographical memory has proposed that 'personal memories' are firmly embedded within the material spaces that we inhabit with other people - in private homes as well as public environments. Places or settings are not regarded as empty spaces where memories become placed; settings contain a 'peopled' past, occupied by sets of relationships, where particular social practices are performed, including rituals, habits and/or official procedures (Geertz, 1973; Casey, 1987). Following Wertsch (2002) we may then treat remembering as a form of 'mediated action' - that is, a form of human action that makes use of 'cultural tools' (including features of the material environment) to accomplish recognisably psychological ends (i.e. recollection of the past). Wertsch's approach to remembering restates the 
Vygotksian position that mediation results in the 'objectification' of human action, as particular mind activities (e.g. thought) can become reconfigured and objectified through material activity (e.g. writing) (van der Veer \& Valsiner, 1991; Cole, 2003). Ambiguity may then emerge in the process of such objectification and in particular as a consequence of what Wertsch calls the 'irreducible tension' between actor and cultural tool during recollection (2002: 11-12)

We wish, however, to extend this definition of mediated action to include not only the cultural tools which are available to actors in their current setting as they engage in recollection, but also the artefacts which were part of the episodes of abuse which are being recollected. In order to bring these artefacts into our analysis we will have to shift towards a slightly different sense of mediation, as it appears in the work of Bruno Latour (2005) and Actor-Network Theory (e.g. Callon, 1991; Law, 2002). If Wertsch's concept of mediated action is informed by Vygotsky and the Soviet philosophical tradition, then Latour's use of the term, whilst kindred in spirit, is simultaneously informed by the work of Michel Serres (1982; 1991), the philosophy of Alfred North Whitehead $(1985 ; 2004)$ and the 'material semiotics' of AJ Greimas (1983; 1985).

From Serres, Latour and Callon derive the idea that social relations are thoroughly intertwined with objects and the material surfaces of the world. Serres (1995) rejects the notion that social relations have some intersubjective 'contractual' basis, emphasising instead that:

Our relationships, social bonds, would be as airy as clouds were there only contracts between subjects. In fact, the object, specific to Hominidae, stabilizes our relationships, it slows down the time of our revolutions. For an unstable band of baboons, social changes are flaring up every minute. One could characterize their history as unbound, insanely so. The object, for us, makes our history slow. (Michel Serres, 1982b/1995: 87) 
For Serres, it is paradoxically the case that there is nothing intrinsically 'social' to social relations. Rather he sees what we call 'the social' as emerging from networks of relations between humans and things. These networked relations allow a transfer of properties and capacities - for example, physical barriers and written signs can replace the need to continuous monitor and instruct the behaviour of others - a process which Serres calls 'translation' (see Brown, 2002). The translation process is what creates the matrix of various forms of human action. Hence Latour sometimes refers to the 'interobjective' basis of human action (see Latour 1996 and the commentary by Engestrom, 1996 for a good illustration of the contrasting uses of 'mediation').

AN Whitehead (1985) provides the key idea that the ascription of identity to a given thing is a higher order process that synthesises or aggregates an assembly of relations. For example, a 'community' is in fact a nexus of relationships evolving over and changing over time, and similarly what we call 'electricity' is an ongoing flow of positively and negatively charged electrons. The point of this observation is that if identity is something ascribed secondarily rather than given in reality then it is erroneous to see action as issuing from identity - rather there is an ongoing process of activity for which identity is a kind of shorthand description. Latour (1996) uses this notion to assert that the proper unit of analysis is the assembly of relations. However, unlike Wertsch, he refuses to distinguish between what is tool and what is actor in this assembly.

Finally, AJ Greimas, the central figure in the so-called 'Paris school' of semiotics, provides the notion that there is a 'generative grammar' of relations out of which all possible signs are derived. Akrich \& Latour (1992) argue that if these relations are understood not as basic meaning units, as semiotics is usually taken to imply, but rather as sets of relational propensities, or ways in which one actor may potentially figure or become relevant for another actor, then Greimasian semiotics can be applied equally to animals, machines or environmental relations (see Greimas, 1985). In all cases, they propose, what needs to be analysed is 
how the actions of one actor become hooked into and mediated by the entire network of others which define a given setting:

Semiotics: The study of how meaning is built, but the word "meaning" is taken in its original nontextual and nonlinguistic interpretation; how one privileged trajectory is built, out of an indefinite number of possibilities; in that sense, semiotics is the study of order building or path building and may be applied to settings, machines, bodies, and programming language as well as texts ... the key aspect of the semiotics of machines is its ability to move from signs to things and back. (Akrich \& Latour, 1992: 259)

The key features of a Latourian approach to mediation are therefore that it concerns the intertwining of human and non-human relations; that it focuses on the literal material associations and the ways these are arranged and 'summed up' in a given assembly; and that it seeks to analyse how actors (non-human as well as human) intervene in and mediate one another's affairs through their relational propensities.

Applied to memory, this approach suggests that objects and artefacts lend something of their seeming stability and potential anchorage in recall. That is to say that recollected events may be inflected not only by the social relations that structure the events, but also by the artefactual or non-human relations present in the setting being recalled. What is recalled is not the behaviour of persons set against some neutral backdrop, but rather an action-complex involving an assembly of relations between people and things. The relational propensities of artefacts may then become embedded in our recollections. Or, put slightly differently, the assembly of relations extends in time as well as space. In recollection the artefacts which participated in the relations being recalled may not literally be present, but their propensities are concretely felt with respect to the 'privileged trajectories' they have constrained and afforded. 
Middleton \& Brown (2005), for example, drawing on Callon (1991), describe how recollections may be 'punctualised' or drawn together around a particular object. A recollection of the moral character of past times and people, for instance, may proceed through a description of the home-made clothes worn at the time (see Middleton \& Brown, 2005: chapter 8). The propensity of objects, how they lend themselves to a collective sense of self-sufficiency, domestic order and moral worth, can and does make a difference to how this past comes to matter in the present. This is not to say that objects somehow determine memory, rather that the way they 'authorise, allow, afford, encourage, permit, suggest, influence, block, render possible [and] forbid' particular actions has concrete resonance in recollection (Latour, 2005: 72). Memory must go by way of the objects.

Our argument here is that ambiguity in adult women's recollections of child sexual abuse involves addressing questions of incidence and intention. These questions coalesce around and are punctualised by objects. For example, a door which is closed and locked raises the question of whether what follows was intentionally constituted as 'private' or 'secretive' (see Hall, 1996; Duncan, 1996). The material features of the settings which afford the possibility of child sexual abuse (often in the habitual privatisation of the home or some other protected institution) can become the focus of recollection. They allow ambiguity to be both posed - what does it mean that he locked the door? why did I let him come into my room? - and to be disposed - he locked it so no-one would know; he violated my private space. In this way ambiguity is both raised and managed in recollection by focussing on how the dispositions of things contribute to the recollected episodes (e.g. doors can make a private space or they can keep other people from knowing what happens - I have come to believe he intended the latter to be the case).

We will now illustrate our argument by describing four examples. These are taken from ten semi-structured interviews with women who have experienced sexual abuse as children. Seven of the women were white, two black and two 
mixed race and six were university educated. Two were self-defined as bisexual, two as lesbian and six as heterosexual (see Reavey, 1998 for further details). Our analysis is theoretically driven, in the sense that we wish to build our argument by way of these examples. However, the point of departure for the argument initially came through the inductive observation that all of the specific memories the participants reported in the interviews conducted contained reference to specific places and artefacts. The examples we present here are good exemplars of what is found throughout the data corpus.

\section{Analysis}

In all of the examples below, recollections of specific events contain reference to ambivalence, in terms of the abuser's or, in examples one and three, the woman's own agency and seeming 'participation' as a child at the time. All of the women are, of course, aware that as children their agency was thoroughly compromised by the actions of the abuser. Yet despite this awareness, the terms of the relationships between themselves and their abuser appear difficult for them to definitively interpret (often demanded by the archetypal victim/abuser plot in culturally available discourses). It is then striking that physical spaces and objects are invoked to pose ambivalence around incidence and intention and to subsequently stabilise it in some way.

In the first example, it is clear that there are a number of alternative open to the speaker about her brother's putative intentions and how they may or may not have resulted in the abuse. What is particularly noteworthy is the manner in which the material mediators (writing and the door) both make it possible to raise the issue of ambiguity surrounding the events (as aspects of pleasure creep in) whilst they ultimately enable an attribution of intentionality to the abusive actor. 


\section{Example one}

It was my brother, we I would think that when he started, it was, er curiosity, but I think, erm...one thing I tried convincing myself of, that that he was naïve and he didn't know what he was doing was wrong, but he used to lock the door to to, we didn't have key locks, he used to take the handle and take out the bar.

[later in the interview]

I'd say the main problem there is is, the guilt for enjoying what he did, and that can really tear me up sometimes, and I think that's been, big problem, actually specifically before I realised the the feeling of confusion, and what I should feel about enjoying this.

I do feel guilty about writing it down, cos it makes it solid, it makes it er, it's evidence and it's just... like I say, it makes it, it makes it real, which of course it was, but some of me wonders how much of it as real...but there's a big part of you that wants to be believe he didn't know what he was doing, but I don't think I can convince myself of that, like I say, going to the extent of locking the door...by the time he got to fifteen, he must have known, he must have done...I think so... but it would have been nice if he didn't.

Would it make a difference?

Yeah because of the way I feel about him, because... because if it was basic curiosity, if if, and, rather than actually knowing that it was 
wrong... he must have known how it would affect me. (Interview three, Lorna; 28 year old white heterosexual woman)

The act of abuse clearly still holds some ambivalence for Lorna. The memory contains a mixture of emotions and sensations (e.g. pleasure, confusion), as well as a set of dilemmas around how to name her experiences as abusive. What is at stake in this passage is the constitution of Lorna's experiences as incidences (of curiosity) or malicious intentional acts carried out by her brother. If the latter can be established, then the 'effects' of these acts can be more readily understood and the identity of Lorna as a survivor more secure. Furthermore, it is the intentional awareness of her brother that is also at stake in the setting up of Lorna's agency - there is interdependency between his and her agency. If his intentions were to do with mere 'curiosity' then it is more likely that her own 'curiosity' would be called into question. Thus, of interest here are the moves made towards managing such emotional ambivalences in the recollection. If ambivalence can be displaced, a more 'solid' ground for trusting that the abuse was real and harmful can be more fully accepted.

The propensities of the door clearly play a key role in the constitution of agency in this recollection. Locks on doors 'close' rooms against uninvited visitors and delineate between public and private spaces. They also lend themselves to establishing an order of things, in terms of the sexual relations that were to take place behind those closed doors. The intentions of the actor become translated and stabilised in relation to the door itself. The person who holds the key is the recognisable character who is in charge of the situation. Thus, we are able to say that the stability of the victim/perpetrator binary is produced through the participation of the objects (key, lock, door) which make up the setting. The intentions of persons are worked out relationally through the contribution of the propensities of things. Objects are called upon to fix, or make stable, the dynamics of the situation being remembered. 
The locking of the door is then taken to be a clear sign of the intended malice behind the act, which subsequently lends weight to the attribution that he must then have been knowingly damaging her sense of self. As Lorna opines:

it makes it, it makes it real, which of course it was, but some of me wonders how much of it as real...but there's a big part of you that wants to be believe he didn't know what he was doing, but I don't think I can convince myself of that, like I say, going to the extent of locking the door...by the time he got to fifteen, he must have known, he must have done.

The judgement of his sexual agency is not based on the exercise of his sexual desire per se (because curiosity would have been more acceptable), it is directed at his ability to forfeit that desire to protect his sister. The brother's agency thus feeds into her own, with the matter settled by the locking of the door. Objects serve here to settle things in the moment and allow Lorna to proceed with a causal narrative of damage. The intention involved in taking off the lock demonstrates to Lorna that ambivalence over her brother's agency can be provisionally placed to one side making it possible for future attributions (by her and others) concerning her wiling participation in this event to be displaced.

\section{Example two}

And what he did was locked me in the bedroom, didn't give me anything to eat, until I basically gave in, or I was a good girl, in his terms...we... and that was really frightening, and the memory I had, but he took all the bedding and all the clothes out of the room....and I remember, the chest of drawers looked like a monster because the drawers weren't there, it'd got this mouth, which was strange. (Interview four, Theresa, 40 year old white lesbian) 
In this extract the relationship between the father and child is marked out and stabilised by the act of locking the door, removing the clothes and drawers and leaving the child alone in a familiar place, altered through the violation of familiar objects (e.g. the monstrous wardrobe). The space of a child's room is replete with references to the familial ordering in a house (Duncan, 1996). Being sent to one's room as a child is an established way for particular moral lessons to be learnt, including learning how to follow a particular parental rule. However, one's room can also be a way to engage with one's desires as a child. The comfort and private space of one's room can afford an engagement with agency, without parental intervention or interruption.

This is clearly not the case for the child Theresa is describing in the extract. The child's space has been usurped by the father who has removed all traces of comfort from her familiar surroundings. The once familiar objects representing security have been removed as a way of substituting verbal interaction and negotiation with static objects that more firmly represent what is at stake (her freedom, human contact and comfort). This scenario is, we would suggest, most likely a condensing of a number of abusive scenes over time (Reavey \& Brown, 2006). However, what is interesting is the way in which the wardrobe, as a monster, has remained memorable for Theresa. It mediates the complex relationship between her and her father, translating it into a more culturally recognisable plot, involving the monstrous villain. Here, her father's monstrous behaviour can be displaced onto the objects in the room, which punctualise a whole complex of relations that Theresa has had to endure with her father, who is read by others, and by Theresa herself, as a kind and loving father. This scene containing the monster object which frightens and breaks the will of the child translates and objectifies the sense of a lack of agency that Theresa describes.

Without such material configurations, intentions and motivations, and thus agency, would have to be read into the father himself who would not potentially 
be as monstrous or frightening, since Theresa experienced the father as both kind AND abusive. Ambivalence can then be translated into a concrete set of relations by the punctualisation of recollection around the wardrobe. The objects stabilise the abuse as something as frightening as a monster, with the drawers establishing a stark concrete reality of fear - something unfamiliar, blank and static. By being locked in the room, the child is forced to confront this fear, which further stabilises the relationship as someone controlled by her abuser.

\section{Example three}

I can remember, having been crossed over the road by my grandma, standing at the gates of this house, and thinking, I don't want to go here, because I knew what was going to happen, but, and I also knew that there was a playground, a but further down, and there were swings and things, which was also very exciting, and I, I can remember wondering whether I could actually go the swings instead of going and seeing this man, and em, and em, I think that I've always felt... why didn't I make the choice, and part of me knows that if l'd gone to the swings my grandma would have found out, one, she would have been extremely angry, and she would have told my mum, and my mum would have been extremely angry, em, two, my grandma would have been terrified, if I wasn't where I'd ought to have been .... my therapist used to say there wasn't an option, because er, I didn't have an option because I was a child... but I can't can't deal with that. (34 year old heterosexual white woman)

The concrete character of the spatial relations described here objectifies the moral order and network of dilemmatics the child is faced with. It also spatialises pleasures in relation to the following choice where; a) the child giving grandma a break by visiting a house where she will become the object of someone else's pleasure; or b) the child engaging in her own pleasure by visiting the park but evoking anger and displeasure in others. 
The 'road' in particular becomes a stable feature of this narrative in that it dramatises the inevitability of the choice - she has to cross the road because her grandma has escorted her to that place. But in that crossing it is as if the 'choice' to be abused has been made, as it is also necessary to return again via this road, and if expectations have not been met (i.e. the child stays in the man's house) severe consequences would have to be faced. The spatialisation of events, through the focus on objects, then makes for a visible and complex moral order. The child may be seen to be acting responsibly towards others. She crosses the road, and in so doing avoids upsetting people who matter. However the introduction of the swings as her 'object' of pleasure, that she could have chosen to indulge in, reiterates her emphasis on the reality of the child's agency. She refuses to take the line (as her therapist encourages her to do) that children are not capable of choice and represents the reality of children's agentic capabilities and pleasures in the objects themselves. The working up of choice, then, through objects is a significant feature of establishing coherence in retrospect.

\section{Example four}

I couldn't forfeit the important relationships in my life, just to stop this abuse happening, so it carried on for about a year...I mean I can remember one time we were sitting on top of this wall, and he came out, and he lifted his daughter down, sort of like you do with a child....and he lifted me down, and he looked over his shoulder and he put his hand between my legs... he didn't have to lift me down like that. It was that that made me realise the lengths he would go to, I don't know why I put up with it and that's when it stopped. (Bella - 37 year old heterosexual white woman). 
In example, four, it is again possible to see how agency constitutes a key feature of Bella's memory. She is struggling to make sense, throughout the interview, of why she 'allowed' the abuse to happen. Here, in this specific memory, she arrives at an explanation that she feels make sense. After describing her home life as replete with neglect, she describes this particular space with her friend positively, and with great fondness. Thus, Bella's defiance and assertion of agency is captured by her 'put[ting] up with the abuse' and by refusing to give up the important relationships in her life. Her recollection is replete with ambivalence precisely due to her defiance regarding the positive relationships in her life and her desire to preserving them. It is interesting that the only clear incident she remembers in the interview involves a particular spatial configuration, around a wall. This occurred in the interview despite a protocol being in place where details regarding the scenes of abuse were to be avoided.

Of interest here is the way in which her encounter with the abuser (her friend's father) is mediated by the wall. As the wall is high Bella must accept help from the abuser in question. Her status as a child, therefore, is reaffirmed by the height of the wall and her smaller physical scale. It also reaffirms her status and position as the child. The wall thus acts as the mediator which establishes the relation of adult provider to child in need of support. Her physical limitations (in being unable to get down from the wall) are thus brought to the fore, and thus her agency in the situation is also subject to questioning. The wall therefore condenses and simplifies the dynamics of power into a more straightforward reading of powerless child and more powerful adult. 
Furthermore, Bella is then able to make to situate the recollected episode with respect to normative 'usual' relationships where adults would respond to the need of the child to be lifted off the wall; that is, with kindness, rather than abuse.

and he lifted his daughter down, sort of like you do with a child... and he lifted me down, and he looked over his shoulder and he put his hand between my legs... he didn't have to lift me down like that. It was that that made me realise...

It is this particular point that the chasm between her relationship to the abuser and her friend's apparently 'normal' relationship to her father is rendered concrete. She appears struck by how adults can and 'ought' to behave and captures a glimpse of the abuser as a loving father who behaved in a protective manner towards his own daughter. Her position as an abused child, therefore, becomes visible through the wall as mediator. The wall is acting to distribute and make clear the position of each of the actors within a set of relationships. Furthermore, the power dynamics are afforded stability through the child's relationship to this concrete object and her inability to prevent the man in taking this as an opportunity to abuse her. In her recollection, the actions mediated by the wall are precisely the point at which she becomes clear about the powerless position she finds herself in more generally. Not only this, in his 'looking around' to see if anyone is watching when he performs this abusive act, a a visible sign is provided to Bella that his act is indeed intentional, which in turn reaffirms his position as the knowing wrongdoer. Her assertion of will then shifts from the 
preservation of her relationship with her friend to stopping the abuse.

\section{Conclusion}

In this paper, we have argued that objects and spaces provide us with a further analytic with which to make sense of the ways in which adult women manage issues of agency in relation to recollections of child sexual abuse. We have focussed on adult women not because we believe that there are inherent gender differences with respect to remembering, but because women's testimony and status as rememberers confronts very particular cultural obstacles, which has significant issues for how questions of agency are worked out. Moreover, whilst our analysis has been theoretically led, we have also wished to confine ourselves to the specific empirical material we have available.

With experiences as potentially complex as child sexual abuse, where ambiguities are felt or anxieties over agency are constantly fought, objects allow ambivalence to be both posed and potentially disposed. There is of course nothing inherent in any given object itself which proved decisive. The objects do not determine the content of recollection - there is no 'essence' or fundamental property of a wardrobe which directly signify 'monster'. But at the same time we do not feel that this 'monstrousness' is purely the result of Theresa's own imaginative associations. We have been guided by a very particular (and not uncontroversial - see Lenoir, 1994) interpretation of semiotics which treats people and things as participants in an assembly of relations, wherein properties and identities are mutually defined and exchanged (or 'translated'). Such assemblies can be considered in terms of the possible trajectories of action and involvement they afford prior to questions of meaning and signification being posed. This sort of 'material semiotics' has gathered substantial ground for the most part outside of psychology (e.g. Brown \& Stenner, 2009; DeLanda, 2005; Latour, 2005; Law, 2004; Massumi, 2002; Mol, 2002; Rotman, 2007). 
We feel this version of semiotics is worthwhile developing within psychological approaches to memory and agency because it has the potential to address some of the conceptual and practical problems which have arisen in the shift away from 'reproductive' to 'reconstructive' accounts of remembering. All too often, reconstructive approaches are taken to be supporting the unsustainable position that matters of accuracy and literal recall are irrelevant. Persons are thereby supposed to be able to say and claim what they like in relation to their own or some collective past. This is most certainly not the case in recollections of child sexual abuse, where details of events can be clearly and literally recalled. But at the same time, there are profound ambivalences within such recollections. We must take into account the individual and social interdependencies in adult womens recollections of child sex abuse (including cultural suspicions over womens testimony), but also, critically, that such recollections are at once both literal/reproductive and imaginative/reconstructive.

Our way through this puzzle has been to argue that the spaces and objects in which abuse occurs serve as participants in prolonging events into the future. Walls, doors, wardrobes, keys all contribute to how the past can come to matter in the present. We have used the strange notion of a 'propensity' of things (see Jullien, 1999). That is to say that a given artefact has a limited capacity or set of affordances which it can contribute to an assembly which subsequently circumscribes the possibilities for recollection. In this way objects can punctualise and objectify ambivalent or indeterminate relations. In so doing they enable ambiguity to be raised as an issue, whilst simultaneously lending something of their propensity to the human actors involved. In the course of recollection, the intentions of humans are, in a sense, borrowed from the propensities of things. If this is so, then analysis of recollections of child sexual abuse needs to acknowledge spaces and things as integral to memory. The ambivalences and certainties of recollections of abuse, anxieties, feelings of pleasure and pain occur in and through peopled spaces. It is their particular configuration which lies 
at the heart of the barely speakable memories which survivors are forced to recall.

\section{References}

Akrich, M. \& Latour, B. (1992) A Summary of a Convenient Vocabulary for the Semiotics of Human and Nonhuman Assemblies. In W. E. Bijker \& J. Law (eds.) Shaping Technology/Building Society: Studies in Sociotechnical Change. Cambridge, MA.: MIT Press.

Antze, P. \& Lambek, M. (eds.) (1996) Tense past: cultural essays in trauma and memory. New York: Routledge.

Armstrong, L. (1994) Rocking the Cradle of Sexual Politics. What Happened When Women Said Incest. London: The Women's Press.

Baker, C. (2002) Female survivors of child sexual abuse. London: Routledge.

Brockmeier, J. (2002) Remembering and forgetting: narrative as cultural memory. Culture and Psychology, 8: 15-43.

Brown, S.D. (2002) 'Michel Serres: Science, translation and the logic of the parasite' Theory, Culture \& Society 19, 3: 1-27.

Brown, S.D. (2008) The quotation marks have a certain importance: Prospects for a 'memory studies. Memory Studies 1, 3: 261-271.

Brown, S.D. \& Stenner, P. (2009) Psychology without foundations: History, philosophy and psychosocial theory. London: Sage.

Brownmiller, S. (1978) Against our will. London: Virago. 
Burman, E. (1994) Deconstructing developmental psychology. London:

Routledge.

Callon, M. (1991) Techno-economic networks and irreversibility, in J.Law (ed) A sociology of monsters: essays on power, technology and domination. London: Routledge.

Campbell, S. (2003) Relational Remembering: Rethinking the memory wars. PLACE: Roman \& Littlewood.

Casey, E. (1987) Remembering: A phenomenological study. Bloomington \& Indianapolis: Indiana University Press.

Draaisma, D. (2000) Metaphors of Memory: A History of Ideas About the Mind. Cambridge: Cambridge University Press.

Duncan, N. (1996) (ed.) Body Space: Destabilising geographies of gender and sexuality. London: Routledge.

Duncan, N. (1996) Renegotiating gender and sexuality in public and private spaces, in N. Duncan (1996) (ed.) Body Space: Destabilising geographies of gender and sexuality. London: Routledge.

Erll, A. \& Nünning, A. (Eds) (2008) Cultural memory studies: An international and interdisciplinary handbook. Berlin: Walter de Gruyter.

Gavey, N. (2005) Just Sex? The cultural scaffolding of rape. London: Routledge.

Greiman, A.J. (1983) Structural semantics: An attempt at a method. Lincoln, Nebraska: University of Nebraska Press. 
Greimas, A.J. (1985) The love-life of the hippopotamus: A seminar with A.J. Greimas. In M. Blonsky (Ed.) On signs. Baltimore: Johns Hopkins Press.

Haaken, J. (2003) Traumatic revisions: remembering abuse and the politics of forgiveness, in P. Reavey \& S. Warner, (2003) (eds.) New feminist stories of child sexual abuse: sexual scripts and dangerous dialogues. London: Routledge.

Haaken, J. (1999) 'Heretical texts: The Courage to heal and the Incest Survivor Movement.' In S. Lamb (ed.) New versions of Victims: Feminists Struggle with the Concept. New York: New York University Press.

Haaken, J. (1998) Pillars of Salt: Gender, Memory and the Perils of Looking Back. London: Free Association Press.

Haaken, J. \& Reavey, P. (Eds) (2009) Memory matters: Contexts for understanding child sexual abuse. London: Routledge.

Hacking, I. (1995) Rewriting the Soul: Multiple Personality and the Sciences of Memory. Princeton University Press: Princeton.

Halbwach, M. (translated by Francis J. Didder, Jr. \& Vida Yazdi Ditter, Introduced by Mary Douglas) (1950/1980) The collective memory. New York: Harper \& Row.

Hall, J. (1996) Geography of child sexual abuse: women's narratives of their childhood environments. Advances in Nursing Science: PAGES

Herman, J.L. (1992) Trauma and Recovery. New York: Basic Books.

Holland, J., Ramazanoglu, C., Sharpe, S. \& Thomson, R. (1998) The Male in the Head: Young people, Heterosexuality and Power. London: Tufnell Park Press. 
Jensen, T.K. (2005) The interpretation of signs of child sexual abuse. Culture and Psychology, 11: 469-498.

Jullien, F. (1999) The propensity of things: Towards a history of efficacy in China. New York: Zone Books.

Kitzinger, J. (1992) Sexual Violence and Compulsory Heterosexuality'. Feminism and Psychology, 2:399-418.

Lamb, S. (1999) 'Constructing the Victim: Popular Images and Lasting Labels'. In S. Lamb (ed.) New versions of Victims: Feminists Struggle with the Concept. New York: New York University Press.

Latour. B. (2005) Reassembling the social: An introduction to Actor-Network Theory. Oxford: Oxford University Press.

Lenoir, T. (1994) Was the last turn a right turn? The semiotic turn and A.J. Greimas. Configurations, 2: 119-136.

Levett, A. (2003) Problems of cultural imperialism in the study of child sexual abuse, in P. Reavey \& S. Warner, (2003) New feminist stories of child sexual abuse: sexual scripts and dangerous dialogues. London: Routledge.

Lowenthal, D. (1985) The past is a foreign country. Cambridge: Cambridge University Press.

McDowell, L. (1996) Spatialising feminism: Geographic perspectives, in N. Duncan. (ed.) Body Space: Geographies of gender and sexuality. London: Routledge. 
McNay, L. (2000) Gender and agency: Reconfiguring the subject in feminist and social theory. Cambridge: Polity Press.

Middleton, D. \& Brown, S.D. (2005) The social psychology of experience: Studies in remembering and forgetting. London: Sage.

Middleton, D. \& Edwards, D. (1990) Collective remembering. London: Sage.

Miltenburg, R. \& Singer, E. (2000) A concept becomes a passion: moral commitment and the affective development of the survivors of child abuse. Theory and Psychology. 10: 503-526.

Mitzal, B. (2003) Theories of social remembering. Buckingham: Open University Press.

Molina, M.E. \& del Rio, M.T. (2007) Child sexual abuse interpretation as a signconstruction process. Culture \& Psychology, 13(1), 29-38.

Moore, H.L. (1994) A passion for difference. Cambridge: Polity Press.

O'Dell, L. (2003) The 'harm' story in childhood sexual abuse: contested understandings, disputed knowledges, in P. Reavey \& S. Warner, (2003) New feminist stories of child sexual abuse: sexual scripts and dangerous dialogues. London: Routledge.

Rasmussen, S. (2002) The uses of memory, Culture \& Psychology, 8: 113-129. 
Reavey, P. \& Brown, S.D. (2007) The embodiment and spaces of memory: child sexual abuse and the construction of agency. Journal of Social Work Practice, 21: 4: 213-129.

Reavey, P., Ahmed, B. \& Majumdar, A. (2006) "How can we help her when she won't tell us what's wrong?" Professionals working with South Asian women who have experienced sexual abuse. Journal of Community and Applied Social Psychology.

Reavey, P. \& Brown, S.D. (2006) Transforming agency and action in the past, into the present time: adult memories and child sexual abuse. Theory \& Psychology, 16, 2: 179-202

Reavey, P. \& Warner, S. (eds.) (2003) New feminist stories of child sexual abuse: sexual scripts and dangerous dialogues. London: Routledge.

Reavey, P. (2003) When past meets present to produce a sexual 'other': examining professional and everyday narratives of child sexual abuse, in P. Reavey \& S. Warner, (2003) (eds.) New feminist stories of child sexual abuse: sexual scripts and dangerous dialogues. London: Routledge.

Reavey, P. \& Warner, S. (2001) Giving up the cure: child sexual abuse and the construction of femininity. International Journal of Critical Psychology. ${ }^{* *}$

Reavey, P. \& Gough, B. (2000) Dis/locating blame: survivors' constructions of self and sexual abuse. Sexualities, 3, 3.

Reavey, P. (1998) Child sexual abuse: professional and everyday constructions of women and sexuality. Unpublished PhD thesis: Sheffield Hallam University. 
Schacter, D. L. (1996). Searching for memory: The brain, the mind, and the past. New York: Basic Books.

Schachter, D.L. \& Scarry, E. (Eds) (2001) Memory, brain and belief. Harvard, Mass: Harvard University Press.

Sebald, W.G. (2002). The rings of Saturn. London: Vintage.

Serres, M. (1982). Hermes: literature, science, philosophy (Eds J.V. Harari \& D.F. Bell). Baltimore: John Hopkins University.

Serres, M. (1991). Rome: The Book of Foundations. Stanford: Stanford University Press.

Serres, M. (1995). Genesis. Michigan: Michigan University Press.

Sutton, J. (1998) Philosophy and Memory Traces: Descartes to Connectionism. Cambridge: Cambridge University Press.

Vygotsky, L. S. (1978) (edited by Michael Cole, Vera John-Steiner, Sylvia Cole \& Ellen Souberman) Mind in action: the development of higher psychological processes. Cambridge Massachusetts: Harvard University Press.

Warner, S. (2000) Understanding child sexual abuse: making the tactics visible. Gloucester: Handsell Press.

Warner, S. (1996a) 'Constructing femininity: Models of child sexual abuse and the production of "woman", in E. Burman, P. Alldred, C. Bewley, B. Goldberg, C. Heenan, D. Marks, J, Marshall, K. Taylor, R. Ullah and S. Warner, Challenging 
Women: Psychology's Exclusions, feminist possibilities, Buckingham: open University Press.

Weedon, C. (1996) Feminist practice and poststructuralist theory. Oxford:

Blackwells.

Weeks, J. (2003) ( $2^{\text {nd }}$ edition) London: Routledge.

Weeks, J. (1985) Sexuality and its Discontents: Meanings, Myths and Modern Sexualities, Routledge and Kegan Paul.

Weldon, M.S. \& Bellinger, K.D. (1997) Collective memory: Collaborative and individual processes in remembering, Journal of experimental psychology: Learning memory and cognition, 23: 1160-1175.

Wertsch, J.V. (2002) Voices of Collective Remembering. Cambridge: Cambridge University Press.

Whitehead, A. N. (1920 / 2004). The concept of nature. Prometheus Books: New York.

Whitehead, A. N. (1927-8 / 1985). Process and reality. The Free Press: New York.

Young, J. E. (2005) At Memory's Edge: After-Images of the Holocaust in Contemporary Art and Architecture. Yale: Yale University Press. Latour 